\title{
Behaviour of the iris vasculature in central retinal vein occlusion: a fluorescein angiographic study of the vascular response of the retina and the iris
}

\author{
L. LAATIKAINEN AND R. K. BLACH \\ From Moorfields Eye Hospital, City Road, London
}

SUMMARY The findings in iris fluorescein angiograms of 48 eyes with central retinal vein occlusion (CRVO) were correlated with the predominant retinal vascular response. In 24 eyes with the nonischaemic type of CRVO there were no or only minimal iris vessel changes, whereas in all 24 eyes with ischaemic type of CRVO there was iris vessel dilatation and leakage with or without neovascularisation. These findings support the hypothesis that hypoxic retina may be a cause of rubeosis iridis in CRVO.

The purpose of this study was to see whether there is any correlation between the behaviour of the iris vessels and the type of central retinal vein occlusion (CRVO). Iris neovascularisation after CRVO was described by Coats (1906). Fluorescein angiography of the iris has shown dilatation of the radial vessels and abnormal leakage of the dye in some cases of CRVO (Raitta, 1968; Raitta and Vannas, 1969; Cappin and Whitelocke, 1974; Kottow, 1976). In our study we have correlated the angiographic findings in the iris with the predominant retinal capillary response to CRVO-that is to say, either dilatation or closure-as shown by fluorescein angiography.

\section{Patients and methods}

Forty-eight patients with a recent CRVO and suitable for both fundus and iris fluorescein angiography were studied at the Retinal Diagnostic Department of Moorfields Eye Hospital in 1975. Either a slit lamp or fundus camera and $5 \mathrm{ml}$ of $20 \%$ sodium fluorescein were used for angiography. Iris and fundus angiograms were taken on separate visits.

Iris angiographies were performed 1 to 52 weeks (average 13 weeks) after the onset of symptoms. In each iris angiogram the presence and source of fluorescein leakage as well as the presence of neovascularisation and ischaemic areas were recorded.

Address for reprints: $\mathrm{Dr}$ L. Laatikainen, University Eye Hospital, Haartmaninkatu 4 C, 00290 Helsinki 29, Finland

\section{Results}

The eyes were separated into two groups according to the predominant features in the retina: (1) a non-ischaemic group, characterised by dilated and leaking retinal vessels (Fig. $1 \mathrm{~A}, \mathrm{~B}$ ); and (2) an ischaemic group with extensive capillary closure (Fig. 1 C). There were 24 eyes in each group.

The main iris changes in the non-ischaemic and ischaemic group of CRVO are shown in Fig. 2 and the Table, which also shows the mean intraocular pressure (IOP) and the mean time after the onset of symptoms when iris angiography was performed in each group.

\section{NON-ISCHAEMIC GROUP}

Fifteen of the 24 eyes showed normal iris vasculature without any leakage of the dye (Fig. 3 A, B). The mean IOP at the time of angiography was $15 \mathrm{mmHg}$ (range 9 to $25 \mathrm{mmHg}$ ). Angiography was performed at 1 to 36 weeks (mean 13 weeks) after the onset of symptoms.

In eight eyes localised vessel dilatation and leakage were found, mainly around the pupil, but radial vessels in general did not leak and no new formed vessels were recognised (Fig. $4 \mathrm{~A}, \mathrm{~B}$ ). The mean IOP was $16 \mathrm{mmHg}$ (range 14 to $19 \mathrm{mmHg}$ ) and the time of study varied from 1 to 24 weeks (mean 12 weeks) after the first symptoms.

In one eye minute new vessels with mild leakage were present on the iris. The IOP was $15 \mathrm{mmHg}$ and angiography was done 11 weeks after the first symptoms. 

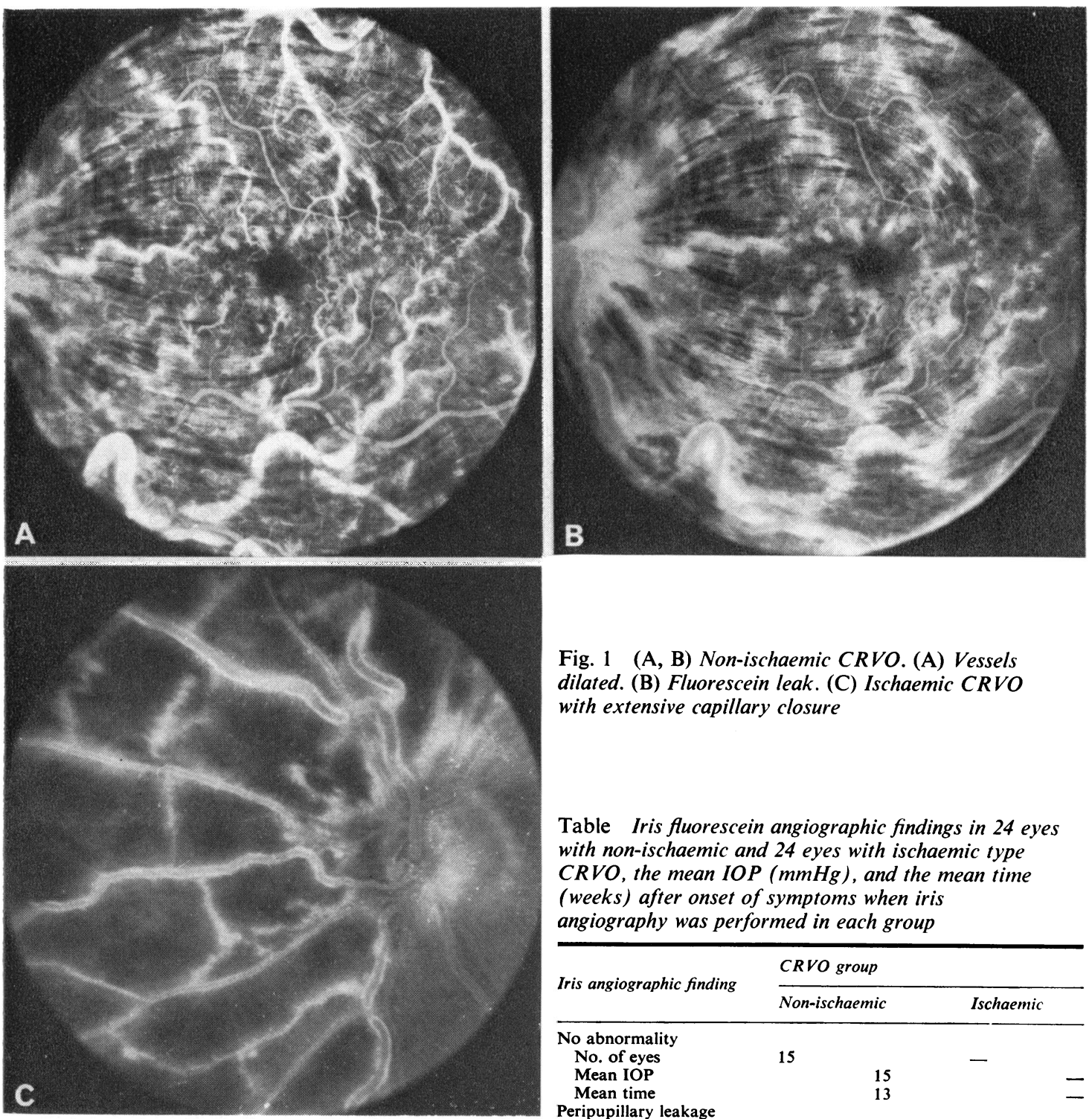

Fig. 1 (A, B) Non-ischaemic CRVO. (A) Vessels dilated. (B) Fluorescein leak. (C) Ischaemic CRVO with extensive capillary closure

Table Iris fluorescein angiographic findings in 24 eyes with non-ischaemic and 24 eyes with ischaemic type $C R V O$, the mean IOP ( $\mathrm{mmHg}$ ), and the mean time (weeks) after onset of symptoms when iris angiography was performed in each group

\begin{tabular}{|c|c|c|c|c|}
\hline \multirow{2}{*}{ Iris angiographic finding } & \multicolumn{4}{|c|}{ CRVO group } \\
\hline & \multicolumn{2}{|c|}{ Non-ischaemic } & \multicolumn{2}{|l|}{ Ischaemic } \\
\hline \multicolumn{5}{|l|}{ No abnormality } \\
\hline No. of eyes & 15 & & - & \\
\hline Mean IOP & & 15 & & - \\
\hline $\begin{array}{l}\text { Mean time } \\
\text { Peripupillary leakage }\end{array}$ & & 13 & & - \\
\hline No. of eyes & 8 & & 2 & \\
\hline Mean IOP & & 16 & & 15 \\
\hline Mean time & & 12 & & 9 \\
\hline \multicolumn{5}{|l|}{$\begin{array}{l}\text { Radial vessel dilatation } \\
\text { and leakage }\end{array}$} \\
\hline No. of eyes & - & & 8 & \\
\hline Mean IOP & & - & & 26 \\
\hline \multirow{2}{*}{\multicolumn{5}{|c|}{ Minimal neovascularisation }} \\
\hline & & & & \\
\hline No. of eyes & 1 & & 6 & \\
\hline Mean IOP & & 15 & & 17 \\
\hline Mean time & & 11 & & 21 \\
\hline \multicolumn{5}{|l|}{ Extensive neovascularisation } \\
\hline No. of eyes & - & & 8 & \\
\hline Mean IOP & & - & & 42 \\
\hline Mean time & & - & & 16 \\
\hline Total No. of eyes & 24 & & 24 & \\
\hline
\end{tabular}

ISCHAEMIC GROUP

All the 24 eyes showed abnormal leakage of dye from the iris vessels. In two eyes vessel dilatation and leakage were restricted to the peripupillary zone corresponding to the findings in the non-ischaemic group. The IOP was $15 \mathrm{mmHg}$ in both and the study was performed nine and eight weeks after the onset of symptoms.

In six eyes small new vessels were seen on the iris with mild leakage (Fig. $5 \mathrm{~A}, \mathrm{~B}$ ). The IOP varied from 13 to $22 \mathrm{mmHg}$ (mean $17 \mathrm{mmHg}$ ) and the study was performed 9 to 52 weeks (mean 21 weeks) 


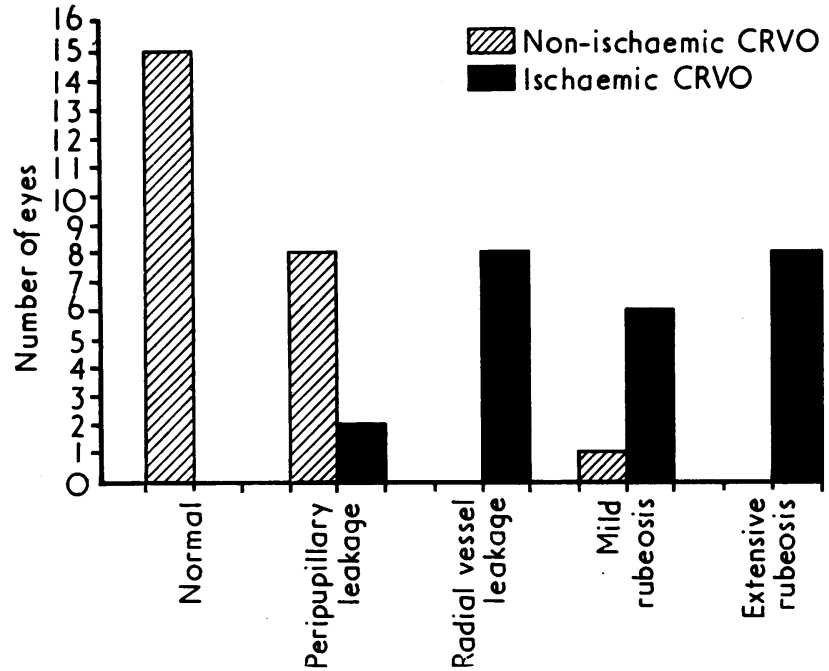

Fig. 2 Distribution of eyes with non-ischaemic and ischaemic CRVO according to predominant findings in iris angiograms after the first symptoms. In most of these eyes the radial vessels were not dilated and did not leak fluorescein.

In eight eyes with ischaemic CRVO the main finding was dilatation of the radial iris vessels with moderate (four eyes) or extensive (four eyes) leakage of fluorescein, but no obvious neovascularisation could be seen in the first angiogram (Fig. $6 \mathrm{~A}, \mathrm{~B}$ ). In these cases the angiograms were taken 1 to 19 weeks (mean eight weeks) after the first symptoms. The IOP varied from 14 to $40 \mathrm{mmHg}$ (mean 26 $\mathrm{mmHg}$ ). In one eye some ischaemic areas were seen in the iris. Six of these eyes developed rubeosis later, during follow-up (Fig. $6 \mathrm{C}, \mathrm{D}$ ), and in five eyes neovascular glaucoma has appeared.

In eight eyes considerable rubeosis with leakage was already seen in the initial angiogram (Fig. 7 A, B). In every eye neovascularisation was found both around the pupil and in the periphery of the iris. In three eyes the radial vessels leaked fluorescein as well. All but one eye had already developed neovascular glaucoma. Therefore the mean IOP in this group was $42 \mathrm{mmHg}$ (range 15 to $63 \mathrm{mmHg}$ ). The time of iris angiography varied from 4 to 36 weeks (mean 16 weeks) after the first symptoms. Two eyes showed areas of iris vessel closure.
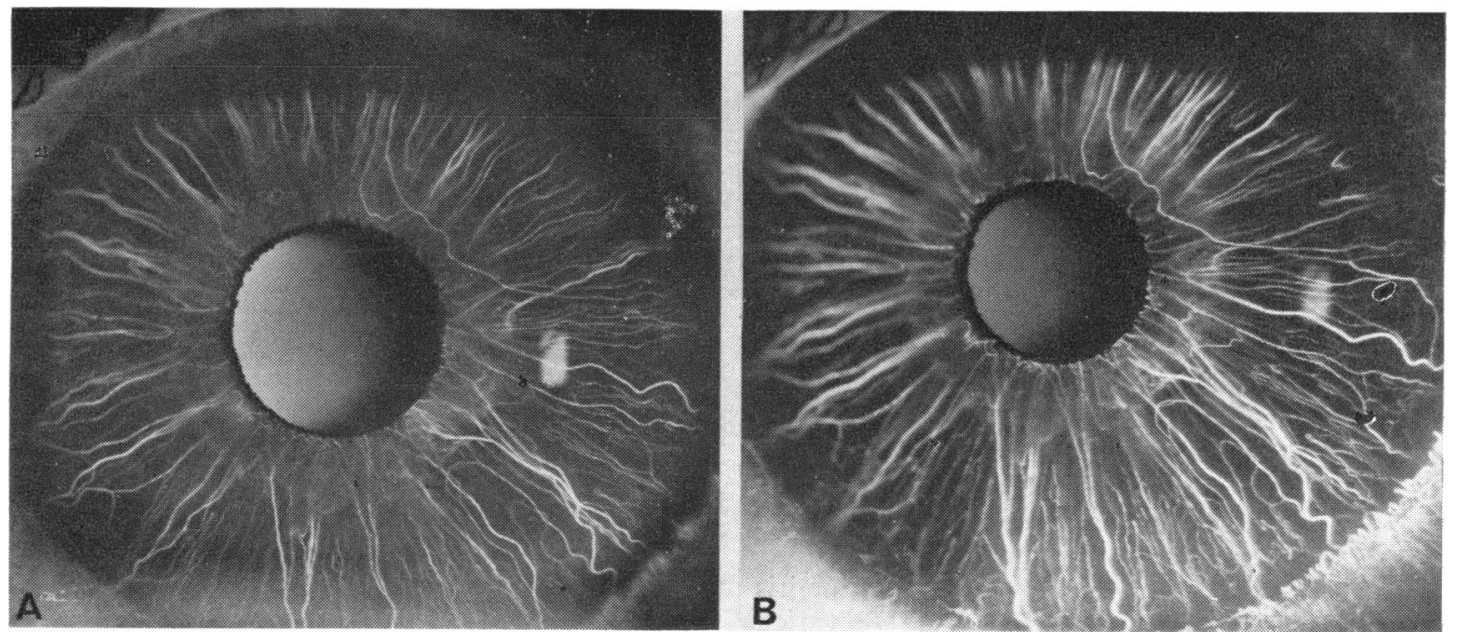

Fig. 3 Iris angiogram in non-ischaemic CRVO. (A) Normal iris vasculature in arteriovenous phase. (B) No fluorescein leakage in late venous phase 

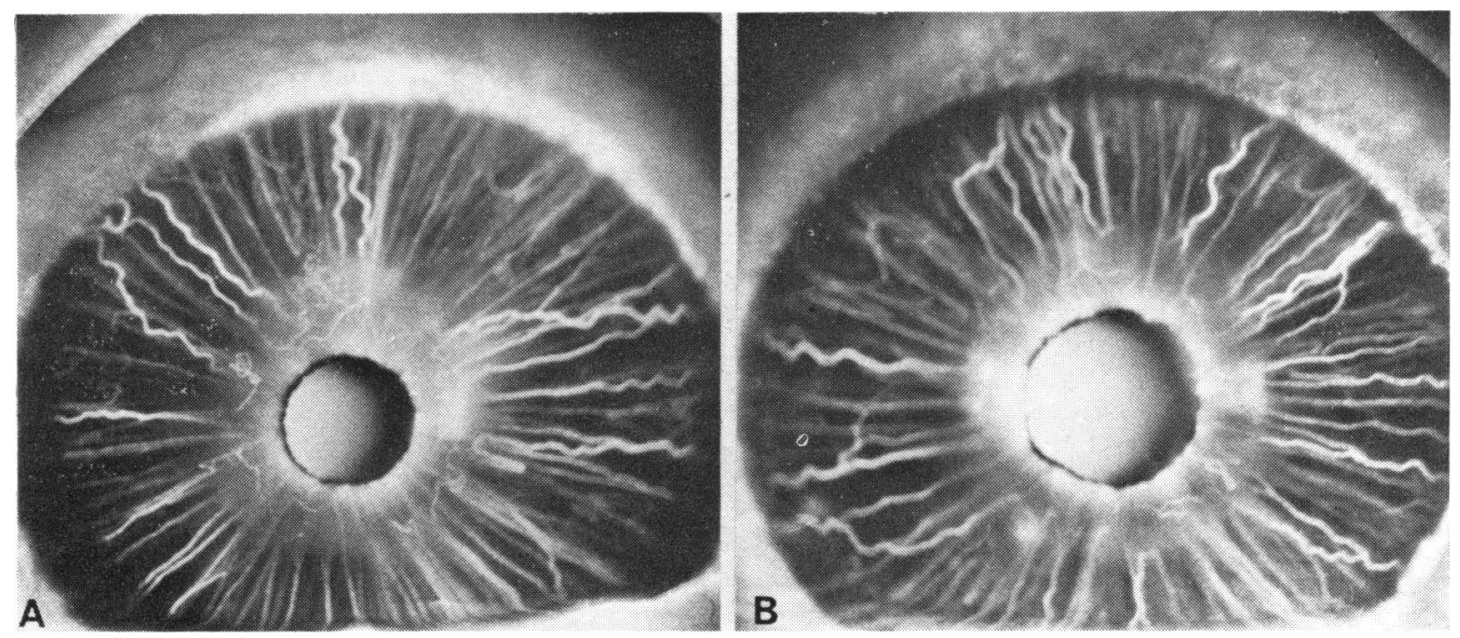

Fig. 4 Iris angiogram in non-ischaemic CRVO. (A) Dilated vessel loops, and (B) leakage around the pupil

\section{Discussion}

Iris fluorescein angiography permits visualisation of the radial arteries and veins as well as larger capillaries. In healthy eyes fluorescein leakage from iris vessels seldom occurs (Vannas, 1969). We found in this study that in most eyes with the non-ischaemic type of CRVO the iris vasculature was normal, although in a few cases mild vessel dilatation and leakage were seen at the pupillary margin. This result could be expected from our previous finding that neovascular glaucoma did not develop in eyes with good retinal capillary perfusion (Laatikainen and Kohner, 1976).

In contrast, in eyes with the ischaemic type of
CRVO rubeosis iridis and neovascular glaucoma are common. In this type, even without glaucoma, angiographic changes of the iris were the rule. The importance of retinal non-perfusion in the development of iris neovascularisation is also supported by Kottow's report (1976), according to which iris vascular alterations were commoner in eyes with fundus neovascularisation than in those without. Fundus neovascularisation after retinal venous occlusion is also related to retinal non-perfusion.

We were unable to take iris angiograms immediately and repeatedly after the onset of the disease. Therefore the exact time of the appearance of the various iris changes could not be accurately known. Dilatation and leakage of the radial vessels seemed,
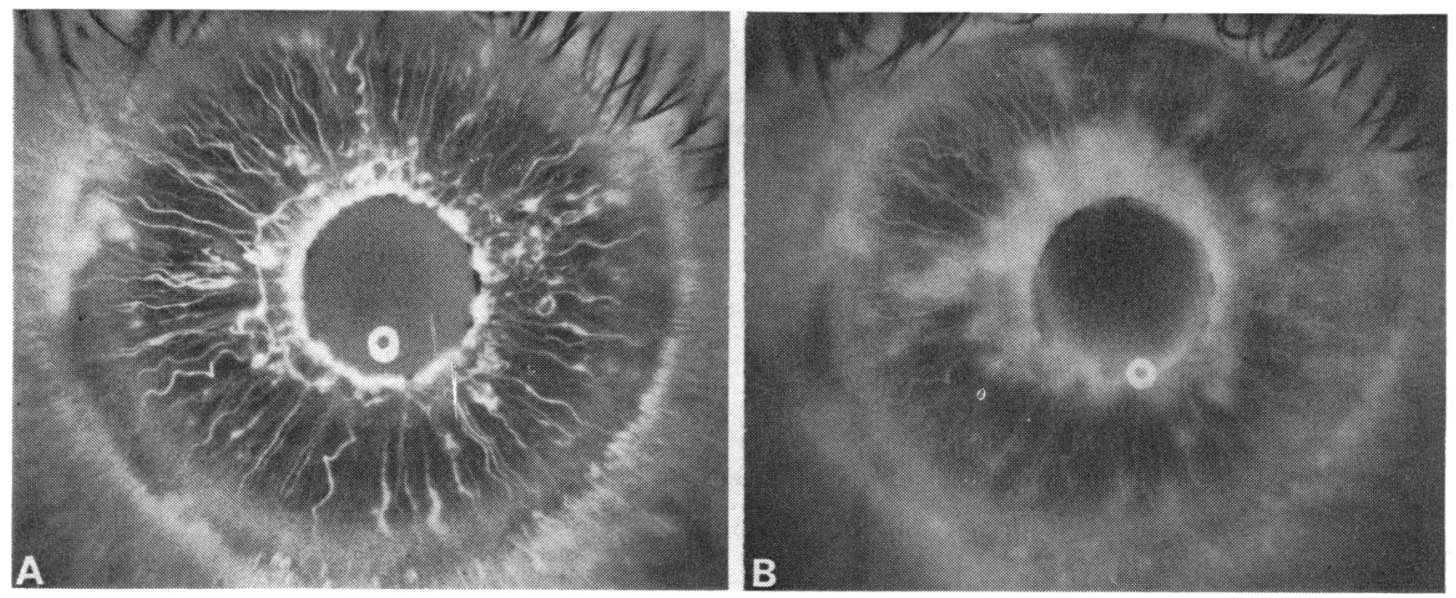

Fig. 5 Iris angiogram in ischaemic CRVO. (A) Small new vessel tufts which (B) leak fuorescein 

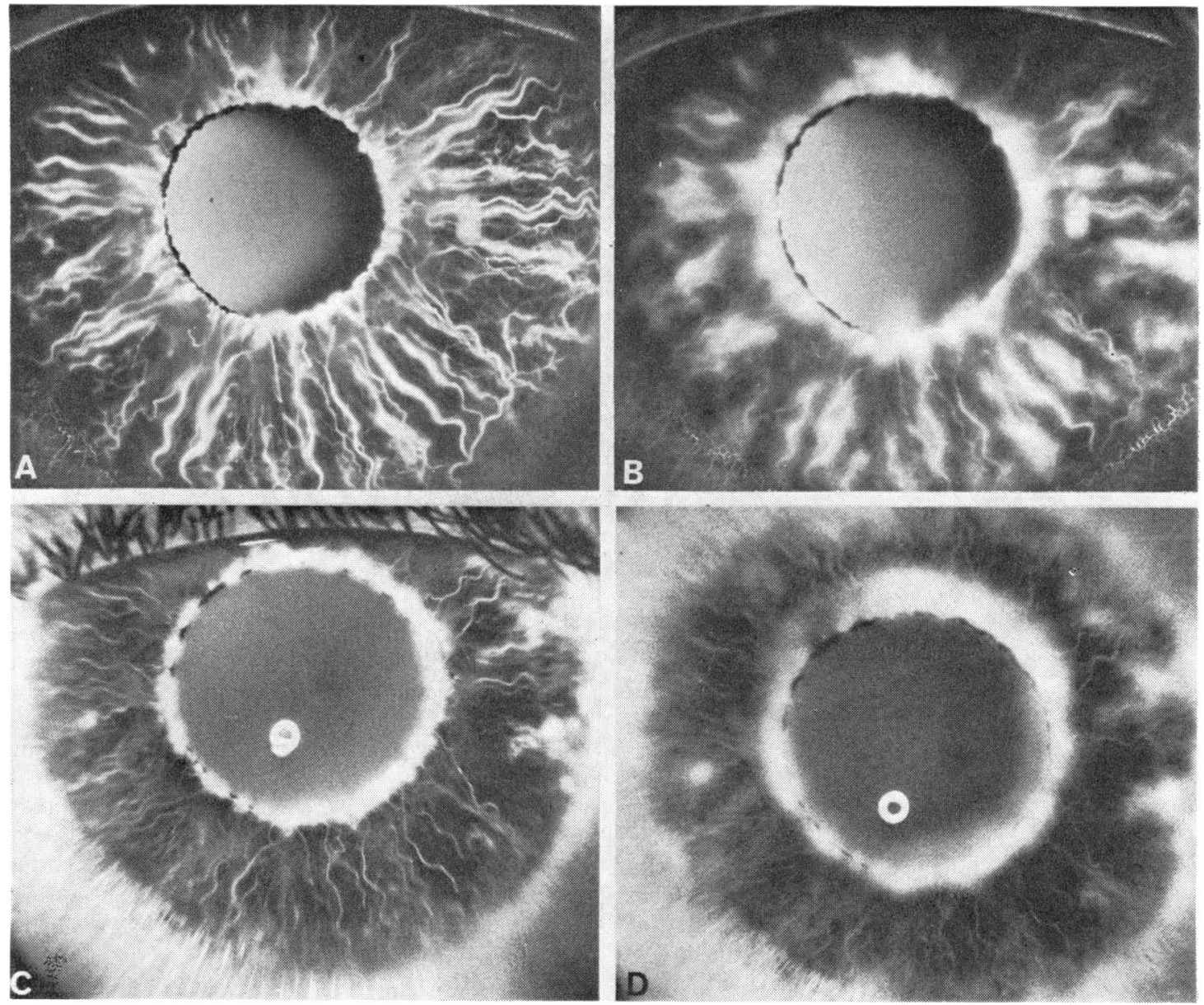

Fig. 6 (A, B) Iris fluorescein angiogram three months after initial symptoms in ischaemic CRVO. (A) Radial vessels dilated and (B) leak fluorescein. 'C, D) Same iris eight months later. (C) Central and peripheral neovascularisation with (D) leakage only from new vessels
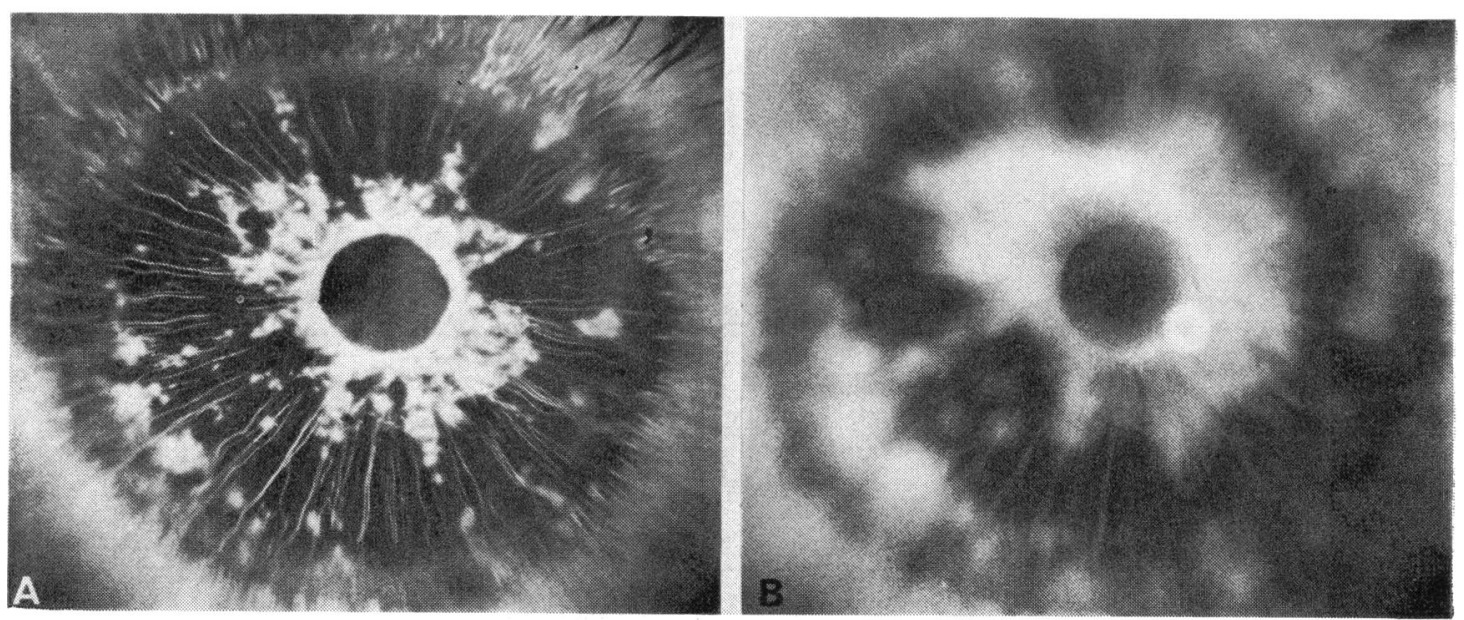

Fig. 7 Iris angiogram in ischaemic CRVO and neovascular glaucoma. (A) Pronounced neovascularisation and (B) leakage of dye from new formed vessels 
however, to precede iris neovascularisation. Similar changes were also described by Vannas and Raitta (1972) in two eyes with CRVO. Later in most early rubeotic eyes radial vessels looked quite normal. Permanent closure of the iris vessels was found only in eyes with a high IOP due to neovascular glaucoma, and therefore vascular closure was possibly secondary to glaucoma. This agrees with the findings of Cappin and Whitelocke (1974), who could not find any signs of defective iris perfusion in early rubeotic eyes.

Iris neovascularisation has been experimentally produced by occluding the long ciliary arteries (Anderson and Morin, 1971). But local vascular insufficiency of the iris would seem unlikely to be the primary cause of rubeosis iridis in CRVO, although the possibility of a transient ischaemia and vessel damage in the iris during the acute stage of the disease could not be excluded. In our cases iris changes closely correlated to the type of the predominant retinal response to CRVO. Destroying the hypoxic retina by photocoagulation also seems to arrest rubeosis (Laatikainen, 1977). These findings support the hypothesis that iris neovascularisation is stimulated by some factor diffusing from the hypoxic retina (Ashton, 1961). The first appearance of neovascularisation around the pupil and in the angle, in the position of maximum turnover of contact with aqueous humour, was also considered by Smith (1961) as an indication of the presence of some vasoformative factor, presumably a product of the hypoxic retina, in the anterior chamber fluid.

Post-thrombotic hypotony has also been suggested as a cause of iris changes. Cappin and Whitelocke (1974) described leakage from radial iris vessels in hypotonic eyes only with tensions of less than $10 \mathrm{mmHg}$. None of the eyes with leaking radial vessels among our cases was hypotonic. This indicates that low IOP was unnecessary for radial vessel leakage or developing rubeosis, and agrees with the findings of Vannas and Raitta (1970) that the incidence of haemorrhagic glaucoma was not increased by post-thrombotic hypotony.

We thank Dr Eva Kohner, who looked after the medical side of these patients, and Mr K. Sehmi for his assistance with the photographs.

\section{References}

Anderson, D. M., and Morin, J. D. (1971). Canadian Journal of Ophthalmology, 6, 196.

Ashton, N. (1961). Transactions of the Ophthalmological Societies of the United Kingdom, 81, 145.

Cappin, J. N., and Whitelocke, R. (1974). Proceedings of the Royal Society of Medicine, 67, 1048.

Coats, G. (1906). Royal London Ophthalmic Hospital Reports, $16,516$.

Kottow, M. H. (1976). Documenta Ophthalmologica, Proc. Ser. No. 9, 465.

Laatikainen, L. (1977). British Journal of Ophthalmology, 61, 278.

Laatikainen, L., and Kohner, E. M. (1976). British Journal of Ophthalmology, 60, 411.

Raitta, C. (1968). Acta Ophthalmologica, 46, 207.

Raitta, C., and Vannas, S. (1969). Albrecht von Graefes Archiv für Klinische und Experimentelle Ophthalmologie, 177, 33.

Smith, R. (1961). Transactions of the Ophthalmological Societies of the United Kingdom, 81, 125.

Vannas, A. (1969). Acta Ophthalmologica, Supplement 105.

Vannas, S., and Raitta, C. (1970). Annals of Ophthalmology, 2, 213.

Vannas, S., and Raitta, C. (1972). Documenta Ophthalmologica, 33, 345. 